UDC 621.039.623:533.9.082

\title{
DIAGNOSTICS AND CONTROL OF FUSION-FISSION HYBRID TOKAMAK- BASED REACTORS: THE TECHNOLOGY FOR MEASUREMENT SYSTEMS
}

\author{
F.P. Orsitto ${ }^{1}$, M. Angelone ${ }^{1}$, M. Tardocchi ${ }^{2}$ \\ ${ }^{1}$ ENEA Department for Fusion and Nuclear Safety, Frascati, Italy \\ ${ }^{2}$ Istituto per la Scienza e Tecnologia dei Plasmi CNR, Milano, Italy \\ A fusion-fission hybrid (FFH) reactor is a complex machine, which includes a tokamak fusion neutron source and two blankets: the trit- \\ ium regeneration and the actinide burner zones. These three systems need their own diagnostics and controls. Problems associated with \\ the implementation and integration of control systems call for a simplified technology. In this paper, the criteria determining the diagnos- \\ tics needs of FFH reactors are reviewed bearing in mind the requirement that the measurements systems should be simple and robust, and \\ their number be limited, considering the space occupied by the blankets. The diagnostics for the tokamak neutron source, including the \\ machine protection and burn control are among the basic equipment. As the fusion and fission blankets can be integrated in a single sub- \\ system their diagnostics must be conceived as an integrated package that includes the means for measuring isotope content, neutron mul- \\ tiplication and effective reactivity of the fission blanket, as well as tritium regeneration in the breeding blanket. The most recent techno- \\ logical developments the field of neutron spectroscopy for fusion and fission blankets are presented, including the diamond and self- \\ powered neutron detectors technology.
}

Key words: fusion-fission reactors, diagnostics, blankets.

DOI: $10.21517 / 0202-3822-2021-44-2-78-85$

\section{ДИАГНОСТИКА И УПРАВЛЕНИЕ ГИБРИДНЫМИ РЕАКТОРАМИ СИНТЕЗА- ДЕЛЕНИЯ НА ОСНОВЕ ТОКАМАКА: ТЕХНОЛОГИЯ ИЗМЕРИТЕЛЬНЫХ СИСТЕМ}

\author{
Ф.П. Орситто ${ }^{1}$, М. Анджелоне ${ }^{1}$, М. Тардокки ${ }^{2}$
}

\begin{abstract}
${ }^{1}$ Национальное агентство по новым технологиям, энергии и устойчивому экономическому развитию (ЕNEA), Отделение термоядерной и ядерной безопасности, Фраскати, Италия

${ }^{2}$ Институт научных и технологических проблем плазмы, Милан, Италия

Гибридный реактор синтеза-деления (ГРСД) представляет собой сложную установку, которая включает в себя токамак, являющийся источником термоядерных нейтронов, и два бланкета: зоны воспроизводства трития и сжигания актинидов. Эти три системы нуждаются в собственной диагностике и своих системах управления. Проблемы, связанные с внедрением и интеграцией специализированных систем управления, требуют упрощённой технологии. В настоящей статье рассматриваются критерии, определяющие потребности в диагностике ГРСД, с учётом требования, чтобы измерительные системы были простыми и надёжными, а их количество было ограничено, учитывая пространство, занимаемое бланкетами. Диагностика источника нейтронов - токамака, включая защиту установки и управление термоядерной реакцией, входит в число основного оборудования. Поскольку бланкеты, в которых будут происходить реакции синтеза и деления, могут быть интегрированы в единую подсистему, их диагностика должна быть спроектирована как интегрированный пакет, включающий средства измерения содержания изотопов, размножения нейтронов и эффективной реактивности бланкета деления, а также воспроизводства трития. Представлены самые последние технологические разработки в области нейтронной спектроскопии для бланкетов, в которых будут осуществляться реакции синтеза и деления, включая технологию алмазных и автономно обеспечивающихся энергией детекторов нейтронов.
\end{abstract}

Ключевые слова: гибридные реакторы синтеза-деления, диагностика, бланкеты.

\section{INTRODUCTION}

The fusion-fission hybrid (FFH) reactor can be viewed as an attractive actinide burning or fusion-assisted transmutation system for the elimination of transuranic nuclear waste [1, 2]. The FFH has three subsystems: i) a breakeven $(Q \sim 1-3)$ tokamak, as a source of $14 \mathrm{MeV}$ neutrons, ii) a fission blanket acting as a transuranic burner, and iii) a tritium breeding fusion blanket. A hybrid load assembly used as a reference in this study, employs a $Q \approx 2$ spherical tokamak [2] as neutron source. FFH diagnostic equipment must complement tokamak measurement systems plus blanket diagnostics, including those used for tritium regeneration and fission characterization. Tokamak diagnostic equipment generally falls into the following subgroups: i) machine protection, ii) basic plasma control, iii) advanced control, iv) physics evaluation and advanced control [3]. Due to the space constraints associated with the fusion and fission blankets, the tokamak of a FFH must have simple equipment for basic plasma control, machine protection and fundamental plasma measurement. In the present study, systems related to the above diagnostics subgroups are discussed: some basic plasma measurements like electron 
temperature are considered as well. The paper introduces the reference tokamak model and summarizes the FFH environmental constraints. It also provides the definitions of terms, such as neutron fluence and damage, and presents the criteria for determining the diagnostic needs of a hybrid reactor: DEMO-like diagnostics and controls (D\&C) for the tokamak neutron source (machine protection and burn control), and the D\&C for both fission and fusion blankets; introduces the diagnostic technology needed for a tokamak neutron source and presents measurements of $14 \mathrm{MeV}$ neutrons, produced by the tokamak neutron source, as well as by single crystal diamond and/or SiC detectors. Furthermore it deals with the diagnostics for the FFH fusion and fission blankets; and presents the conclusions.

\section{REFERENCE TOKAMAK MODEL AND ENVIRONMENTAL CONSTRAINTS}

The diagnostics needs for a FFH can be more precisely determined using models as a reference for the evaluation of systems to be implemented. Table 1 shows the main parameters of FFH models compared with the ITER design.

$\mathrm{T}$ a b l e 1. Parameters of tokamaks proposed as FFH neutron sources vs ITER parameters

\begin{tabular}{l|c|c|c|c|c}
\hline \multicolumn{1}{c|}{ Parameter } & FDS-I (China) & SABR (USA) & CFNS (USA) & FNS (RF) & ITER \\
\hline Major radius, $\mathrm{m}$ & 4 & 3.75 & 1.35 & 3.2 & 6.2 \\
Aspect ratio, $(R / a$ = major radius/minor radius) & 4 & 3.4 & 1.8 & 3.2 & 3.1 \\
Magnetic field, T & 6.1 & 5.7 & 2.9 & 5 & 5.3 \\
$Q\left(P_{\text {fus }} / P_{-}\right.$auxiliary heating) & 3 & 3 & 2 & 2 & 10.0 \\
$P_{\text {fus }}, \mathrm{MW}$ & 150 & 180 & 100 & 60 & 400.0 \\
Average neutron wall loading, $\mathrm{MW} / \mathrm{m}^{2}$ & 0.5 & 0.6 & 0.9 & 0.2 & 0.57 \\
Plasma elongation & 1.78 & 1.7 & 3 & 2 & 1.7 \\
Triangularity & 0.4 & & & 0.5 & 0.33 \\
$q$, safety factor & 3.5 & 3 & 2.5 & 4.4 & 3 \\
Plasma current, MA & 6.3 & 8.3 & 10 & 5 & 15 \\
\hline
\end{tabular}

We can use the Kadomtsev similarity parameter, $S_{k}[10-12]$ to define similar plasmas, i.e. plasmas with the same confinement properties $(R$ is the tokamak major radius, $B$ is the on-axis toroidal magnetic field, $A$ is the aspect ratio $R / a: S_{k}=R B^{4,5} A^{-3 / 2}$. Fig. 1 shows $S_{k}$ for the devices included in Table I.

It is clear from Fig. 1 that FDS-I, SABR and FNS parameters are more or less similar. All have an either 2 or 3 fusion gain $Q$. The difference between the above FFH models and ITER lies in the level of their availability and the pulse length, which must be of the order of $75 \%$ and at least $3 \mathrm{hrs}$, respectively, for a tokamak neutron source useful for FFH. These characteristics are

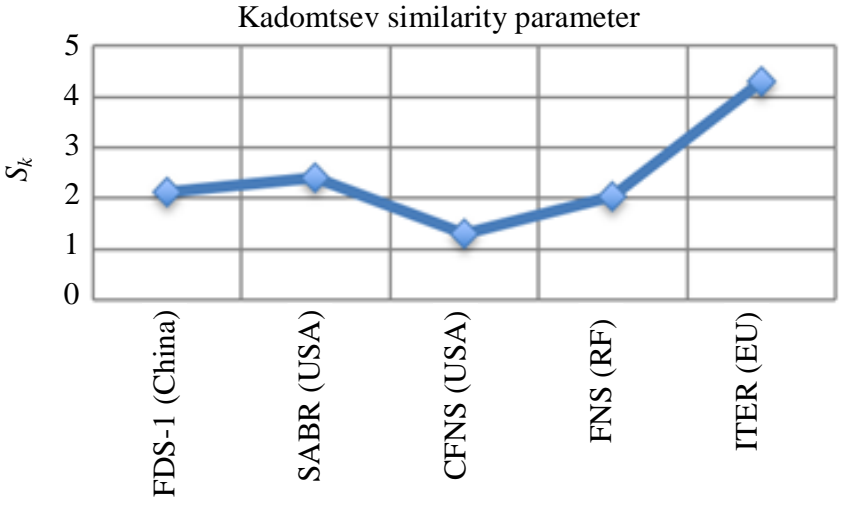

Fig. 1. Similarity parameters evaluated for FFH reactors models considered in Table 1 there in the DEMO tokamak reactor. In fact, some guide-

lines applied to DEMO diagnostics can be also useful for determining FFH diagnostic systems, if we regard a FFH tokamak neutron source as a low power/low gain DEMO-like reactor. The following criteria can be identified as a basis for determining the FFH diagnostic systems [4]:

- a plasma scenario is available (assessed): no specific measurements are made in respect to a physics scenario evaluation, the physics scenario model is assumed known;

- measurements are needed for: assessing the machine protection and safety, including the divertor and PWI (plasma wall interaction); controlling the plasma scenario (including DT-reactions/burn control and neutron production): controlling tritium production; controlling the fission blanket;

- in particular, since available space will be used primarily to maximize the fusion and fission blankets, diagnostics for machine protection and plasma scenario/burn control should be minimal.

Evaluating the magnitude of a FFH tokamak neutron fluence (neutrons $/ \mathrm{m}^{2}$ or $\mathrm{MW} \cdot \mathrm{a} / \mathrm{m}^{2}$ ) would be useful. To this end, the CFNS machine (internal surface, $S \approx 100 \mathrm{~m}^{2}$ ), producing $100 \mathrm{MW}$ of DT (deuterium-tritium) fusion power with availability of $50 \%$ in one year will be used as a reference. Assuming that $100 \mathrm{~W}$ fusion cor- 
responds to $80 \mathrm{MW}$ of $14 \mathrm{MeV}\left(14 \mathrm{MeV}=2.24 \cdot 10^{-12} \mathrm{~J}\right)$ neutron power, this gives a neutron flux, $\varphi=80.0 \cdot 10^{6} /\left(100 \mathrm{~m}^{2} \cdot 2.24 \cdot 10^{-12} \mathrm{~J}\right)=3 \cdot 10^{17} \mathrm{n} /\left(\mathrm{s} \cdot \mathrm{m}^{2}\right)$. Integrating this flux over 120 days (i.e., one year $=240$ days) of operation per year, we obtain a neutron fluence of $3 \cdot 10^{24} \mathrm{n} / \mathrm{m}^{2}$. The ITER neutron fluence (assuming that $400 \mathrm{MW}$ fusion power corresponds to $320 \mathrm{MW}$ of $14 \mathrm{MeV}$ - neutron fusion power, the ITER availability is $7 \%$ a year and inner surface of the ITER vessel, S_ITER $\approx 200 \mathrm{~m}^{2}$ ) is $1 \cdot 10^{24} \mathrm{n} / \mathrm{m}^{2}$ for 16.8 effective day reactor operation. The CNFS fluence is three times as large as that of ITER for one year of operation and is therefore well sustainable even with currently available FW materials.

Minimum machine protection diagnostic set. Table 2 shows a possible minimum diagnostic set for the tokamak machine protection (see [4] for additional details of the DEMO diagnostic systems and [5] and [6] for those of FFH).

$\mathrm{T}$ a b 1 e 2. Minimum machine protection diagnostic set

\begin{tabular}{l|c}
\hline \multicolumn{1}{c|}{ Magnetics } & Sensors: hall probes \\
\hline \multicolumn{1}{c}{ Runaway electrons and control by Cherenkov radiation detection } \\
\hline IR cameras & W or Mo mirrors \\
Polarimetry (poloidal and toroidal) & W or Mo mirrors) \\
Plasma position reflectometry (waveguides to be tested) & - \\
Fission chambers and diamond detectors & - \\
$X$-ray spectroscopy & - \\
VUV and V spectroscopy & - \\
\hline
\end{tabular}

In general, the machine protection diagnostics already studied for the ITER case can be used as a template for a FFH reactor: however, as suggested above, the neutron damage of the diagnostic system components, such as the Hall sensors, the waveguides or the first mirrors, can be higher for a FFH than for ITER. That is why for a FFH reactor, $\mathrm{R}$ and $\mathrm{D}$ of the neutron damage for the diagnostic system components should be set at the level of fluence evaluated above. A minimum machine protection diagnostic set should include the following:

- magnetics for equilibrium evaluation: the Hall probes measure the magnetic flux. They are very useful for measuring long pulses and are resistant to high neutron fluxes;

- combined polarimetry/interferometry tools to measure the DL line integrated density and determine, through Faraday rotation and Cotton-Mouton phase shift measurements, the equilibrium with internal (relative to the plasma) constraints. Polarimetry can also allow a rough evaluation of electron temperature $T_{e}$ averaged over the line of sight for $T_{e} \approx 10 \mathrm{keV}$;

- IR cameras for measuring the temperature of the wall and divertor tiles;

— fission chambers, diamond/SiC detectors and activation foils for the measuring tokamak neutron yield;

- spectroscopy measuring plasma impurities;

- Cherenkov probes and hard X-ray spectrometers for measuring the runaways.

Burn Control in a plasma scenario on a tokamak-based FFH reactor. Burn control in plasma scenarios implies the use of a complex matrix, shown in Table 3.

$\mathrm{T}$ a b l e 3. Burn control matrix for a plasma scenario

\begin{tabular}{|c|c|c|c|c|c|}
\hline Actuator & $\begin{array}{c}\text { Plasma parameter } \\
\text { controlled }\end{array}$ & Availability & Actuator output controlled & Latency & $\begin{array}{l}\text { Hardware } \\
\text { response time }\end{array}$ \\
\hline ECRH, NBI & $\begin{array}{l}\text { Temperature and } \\
\text { density profiles }\end{array}$ & All scenarios & Angle of ECRH launcher & $<1 \mathrm{~s}$ & $<1 \mathrm{~s}$ \\
\hline ECRH, NBI, Central solenoid & Conductivity profiles & Current rise & Angle of ECRH launcher & $<1 \mathrm{~s}$ & $<5 \mathrm{~s}$ \\
\hline Impurity seeding $(\mathrm{Ar}, \mathrm{N})$ & $\begin{array}{c}\text { Radiation profile } \\
\text { (divertor detachment }\end{array}$ & All scenarios & $\begin{array}{l}\text { Impurity flux and density, } \\
Z_{\text {eff }} \text { (dilution, fusion power) }\end{array}$ & $<0.1 \mathrm{~s}$ & $<1 \mathrm{~s}$ \\
\hline Deuterium gas injection & Density & All scenarios & Isotopic mix (fusion power) & $<0.1 \mathrm{~s}$ & $<1 \mathrm{~s}$ \\
\hline Tritium (NBI or pellet) & Central fuelling & All scenarios & Isotopic mix (fusion power) & $<1 \mathrm{~s}$ & $<1 \mathrm{~s}$ \\
\hline ESRH System & Parallel current & Steady state scenario & Angle ECRH launcher & $<1 \mathrm{~s}$ & $<1 \mathrm{~s}$ \\
\hline NBI & Plasma rotation & All scenarios mainly steady state & NBI power & $<1 \mathrm{~s}$ & $<1 \mathrm{~s}$ \\
\hline PF System & Plasma boundary & All scenarios & $\begin{array}{c}\text { Higher ordet moment of } \\
\text { boundary shape or gas }\end{array}$ & $<1 \mathrm{~s}$ & $<1 \mathrm{~s}$ \\
\hline
\end{tabular}

The burn control matrix includes a column for actuator as well as columns for plasma parameter controlled (and diagnostic system used), the scenario and actuator output to be controlled, the latency (maximum time delay of the actuator response from the sensor input), and hardware response time.

For example, an actuator in the form of a neutral beam injector (NBI) is used to control plasma rotation, while the sensor (diagnostic) would be the spectroscopy (active or passive), this control is needed mainly in the 
advanced tokamak scenario, the power of the NBI controls the plasma rotation, and both the latency and the hard ware response time must be less than $1 \mathrm{~s}$.

From Table 3 it can be seen that the main burn control quantities are: temperature and density profiles resolved in time, impurity content, rotation spatial profiles, and radiation profiles. The neutronics is central to fusion power monitoring. Listed in Table 4 are potential neutron measurement high tech sensors.

$\mathrm{T}$ a $\mathrm{b}$ l e 4 . Neutron diagnostics versus measurements

\begin{tabular}{|c|c|c|c|c|}
\hline Parameter & Neutron camera & Fission chamber & Activation foils & Spectrometer \\
\hline Fission power & Possible to measure parameter & Primary method & $\begin{array}{l}\text { Provide supplemen- } \\
\text { tary/relate information }\end{array}$ & \\
\hline Fission power density & Primary method & $\begin{array}{l}\text { Provide supplemen- } \\
\text { tary/relate information }\end{array}$ & $\begin{array}{l}\text { Provide supplemen- } \\
\text { tary/relate information }\end{array}$ & \\
\hline Total neutron flux & Possible to measure parameter & Primary method & $\begin{array}{l}\text { Provide supplemen- } \\
\text { tary/relate information }\end{array}$ & \\
\hline 1st wall fluence & $\begin{array}{c}\text { Provide supplementary/relate } \\
\text { information }\end{array}$ & $\begin{array}{l}\text { Provide supplemen- } \\
\text { tary/relate information }\end{array}$ & Primary method & \\
\hline Fuel ratio & Possible to measure parameter & & & Primary method \\
\hline Runaway & $\begin{array}{c}\text { Provide supplementary/related } \\
\text { information }\end{array}$ & & & \\
\hline MHD instabilities & Possible to measure parameter & & & \\
\hline Ion temp distribution & Possible to measure parameter & & & $\begin{array}{l}\text { Provide supplementary/relate in- } \\
\text { formation }\end{array}$ \\
\hline
\end{tabular}

Table 4 is set out to show what diagnostic system is appropriate and useful (and to what extent) in controlling a given parameter. For example, the fusion power is measured mainly by fission chambers giving the neutron yield (in neutrons/s); where as the fusion power density is measured primarily by a neutron camera, which allows neutron fluxes to be measured along different lines of sights (usually the same lines of sights are shared with gamma ray sensors to detect gamma ray emitted by interactions between fusion alpha particles and impurities). Fusion power and neutron flux feedback control is needed to keep constant the hybrid reactor's global power. The $k_{\text {eff }}$ (effective criticality coefficient of the fission blanket) decreases with the fuel fissioning up, in which case the fusion power (the number of neutrons) needs to be increased. The main plasma parameters to be controlled are plasma density and dilution and $T_{e}$, consequently the main actuators are the NBI power and the gas injection valves.

\section{DIAGNOSTIC TECHNOLOGY NEEDED FOR A TOKAMAK NEUTRON SOURCE: MEASURING 14 MEV NEUTRONS PRODUCED BY A TOKAMAK NEUTRON SOURCE USING SINGLE CRYSTAL DIAMOND AND/OR SIC DETECTORS}

This section addresses recently developed neutron measurement technologies represented by single crystal diamond detectors (SCDDs) for quantifying DD (2.5 MeV) and DT (14 MeV) neutrons. A SCDD $[7,8]$ is a compact device, suited to harsh environments and characterized by high-intensity neutron fluxes and high temperature. The device is insensitive to magnetic fields and little sensitivity to gamma radiation background. Furthermore, SCDDs have high energy resolution $(<1 \%)$. Their neutron detection technology relies on the collection of electrons and holes that are generated by charged particles in nuclear reactions induced by neutrons on carbon nuclei: an energy of $13 \mathrm{eV}$ is needed to produce an electron-hole pair. The following neutron-induced nuclear reactions on ${ }^{12} \mathrm{C}$ are used to detect neutrons:

i) the $n-\alpha$-reaction: $n+{ }^{12} \mathrm{C}={ }^{9} \mathrm{Be}+\alpha(Q=-5.7 \mathrm{MeV}$, threshold energy $6.17 \mathrm{MeV})$;

ii) elastic neutron scattering on ${ }^{12} \mathrm{C}$ nuclei: $n+{ }^{12} \mathrm{C}=n+{ }^{12} \mathrm{C}$;

iii) $n$-3 $\alpha$-reaction: $n+{ }^{12} \mathrm{C}=n^{\prime}+3 \alpha(Q=-7.23 \mathrm{MeV}$, threshold energy $7 \mathrm{MeV})$.

For the $2.5 \mathrm{MeV}$ DD-neutrons, the only detection path available is via elastic scattering, while for the $14 \mathrm{MeV}$ DT-neutrons, i) reactions, ii) and iii) are available as well. 
Fig. 2 shows a remarkable measurement of $14 \mathrm{MeV}$ neutron calibration using the Frascati Neutron Generator (FNG).
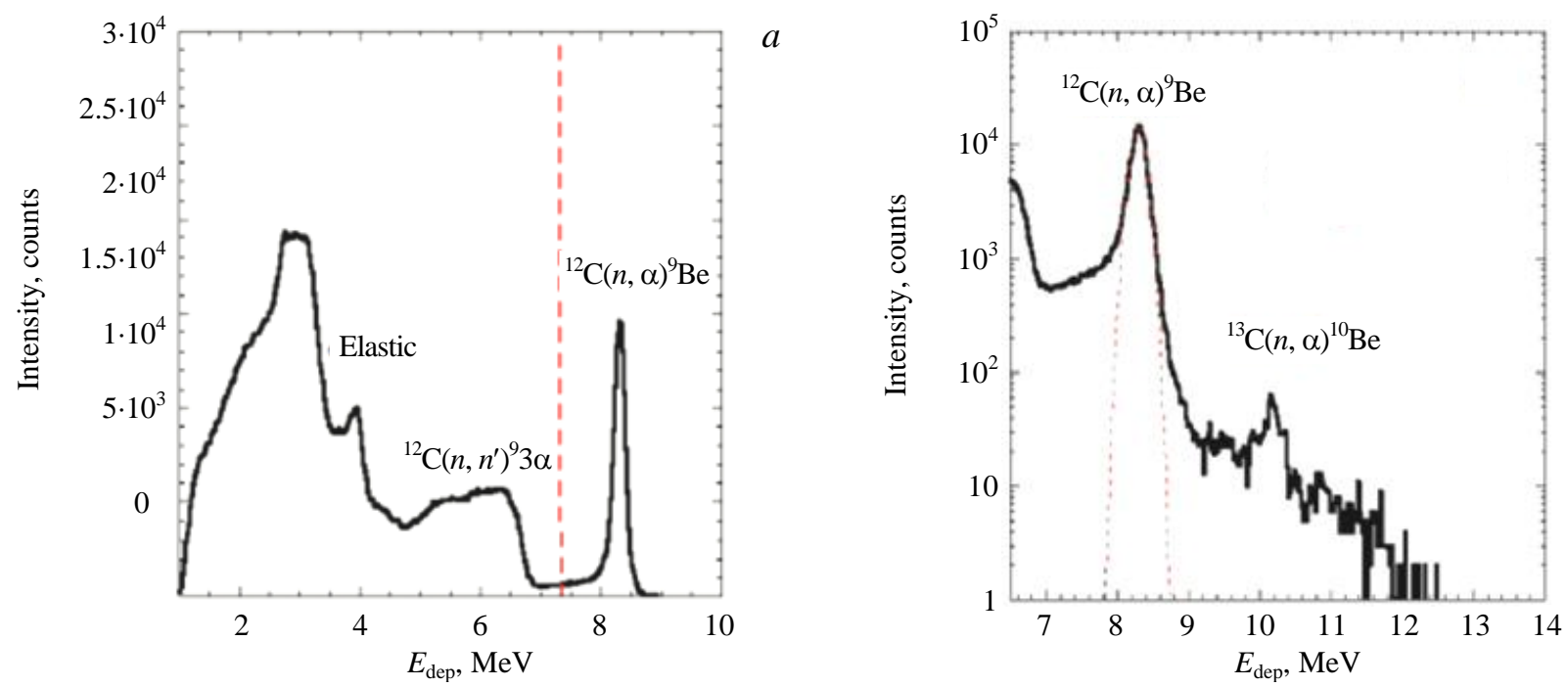

Fig. 2. Linear $(a)$ and log-linear $(b)$ signals measured with the single crystal diamond detector using the FNG 14 MeV neutron generator: - measurement, $\cdots \cdots$-... - gauss fit

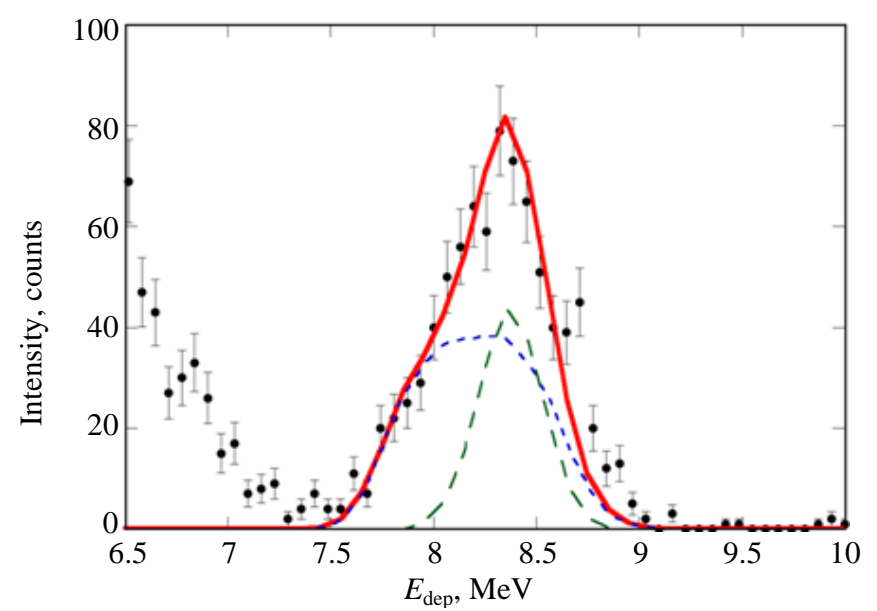

Fig. 3. $14 \mathrm{MeV}$ neutron spectroscopy performed by SCDD; the components of neutrons produced in collisions of DT-reactions tritium beams with thermal ions and thermal deuterium and tritium nuclei: — - fit, ----- — beam-th, - - - - th

of fusion plasmas in selected robust plasma scenarios $\left(Q_{\text {thrm }} / Q_{\text {on }}\right.$ ). A neutron monitor can be used to measure the overall neutron yield (including the multiplication factor due to the fission part). The ITER experience suggests that the diagnostics integration is a very challenging endeavour. Solutions studied for ITER, could be beneficial for FFH, although need to be FFH-specific.

\section{FUSION-FISSION HYBRID'S FUSION AND FISSION BLANKET DIAGNOSTICS}

The FFH reactor system consists of three subsystems: a tokamak neutron source, a tritium producing blanket, and a fission blanket. Measurements are therefore needed to monitor:

- the fission rate of main transuranic (TRU) elements;

— the secondary (relative to fission) neutron production;

- tritium production and the tritium breeding ratio.

Sensors can be inserted in the blankets to determine the status of tritium production and the fission of TRU elements.

Fusion blanket diagnostics. A first list includes both passive and active detectors: active detectors:

- (micro) fission chambers (FCs);

- self-powered neutron detectors (SPNDs) for total neutron/gamma flux measurements; 
— diamond/SiC sensors (coated with ${ }^{6} \mathrm{LiF}$ films for tritium measurement) and SPNDs with ${ }^{\text {Nat. }}$ LiF coatings, used as emitters or lithium-based detectors (time dependent tritium production): (micro) ionization chambers (ICs) for gamma dose-rate measurements.

Passive detectors: nuclear activation system.

The SPNDs [9] are rugged miniature devices (Fig. 4) that have long been used for in-core fission reactor monitoring (for safety and neutron/gamma flux mapping purposes). SPNDs operate without any applied voltage, which enhances their reliability and resistance to radiation from the reactor core. The detectors are usually constructed in a coaxial configuration, in which the central conductor (called the emitter) material usually determines the device characteristics. The other electrode or metallic sheath is called the collector, and the two are separated by a (coaxial) mineral insulator.
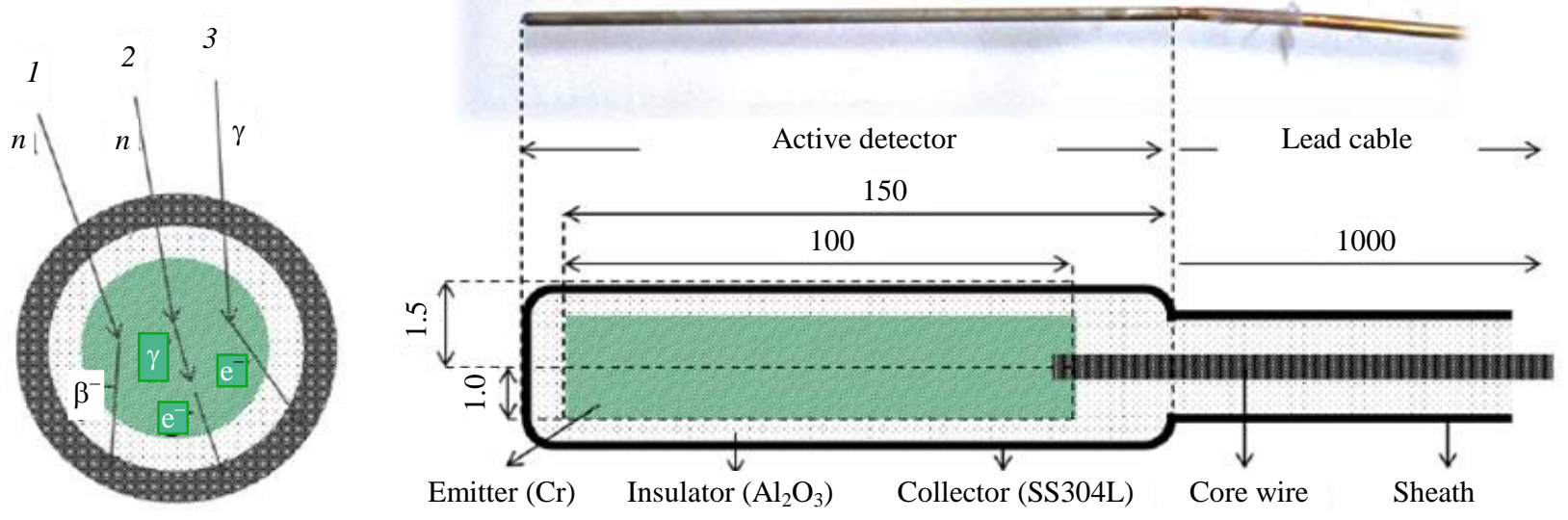

Fig. 4. Scheme of a SPND detector

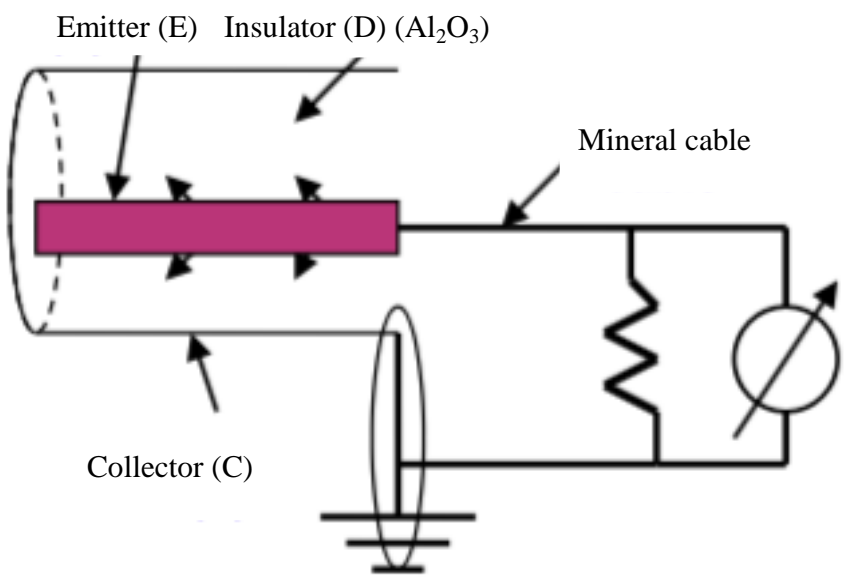

Fig. 5. SPND electrical circuit

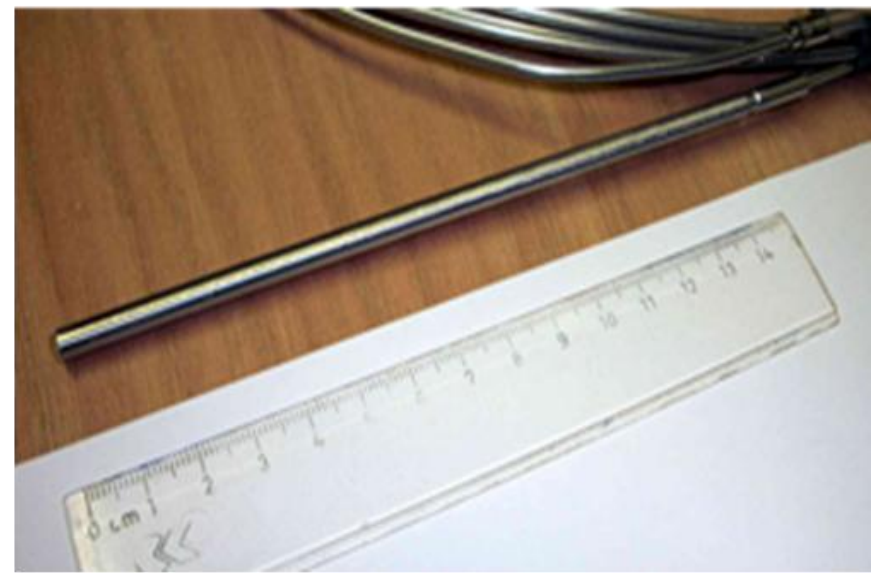

Fig. 6. ENEA CNPD prototype detector based on a Cr emitter

The SPND operates on the basis of measuring a beta decay (decay in electrons) related to a metastable state created by the interaction of the neutron with the emitter (in green in Fig. 4) which can essentially be either of the following materials: chromium, cobalt, vanadium or rhodium. Generated electric signal is compared to the collection on the 'collector' (in Fig. 4, one can see that the collector is made of stainless steel) of the electrons generated through the beta decay. The SPND electrical circuit is shown in Fig. 5.

In commercial SPNDs (used in fission reactors), the emitter (metal)_material has at least a moderate neutron capture cross-section at thermal neutron energy_allowing activation products to decay through beta_emission. Because the neutron spectrum generated by a fusion FFH neutron generator has higher energy, commercial emitters are not suitable. Consequently, prototype SPNDs whose emitters are suitable for fast neutron spectrum (enough beta activation) are presently developed at ENEA and KIT. Two prototypes detectors fabricated $(\mathrm{Cr}$ and $\mathrm{Be}$ emitter) ENEA developed the SPND_Cr, KIT the $S P N D \_B e$. Fig. 6 shows a Cr-based prototype SPND implemented at ENEA: it is $10 \mathrm{~cm}$ long and has a $2 \mathrm{~mm}$ across $\mathrm{Cr}$ emitter (5.5 gr), and a $10 \mathrm{~m}$-long mineral cable (SS-304 sheath and $\mathrm{Al}_{2} \mathrm{O}_{3}$ insulator).

Tests were performed on the SPND_Cr prototype using the FNG (frascati neutron generator, REF) $14 \mathrm{MeV}$ neutron source and a strong ${ }^{60} \mathrm{Co}$ gamma-ray 


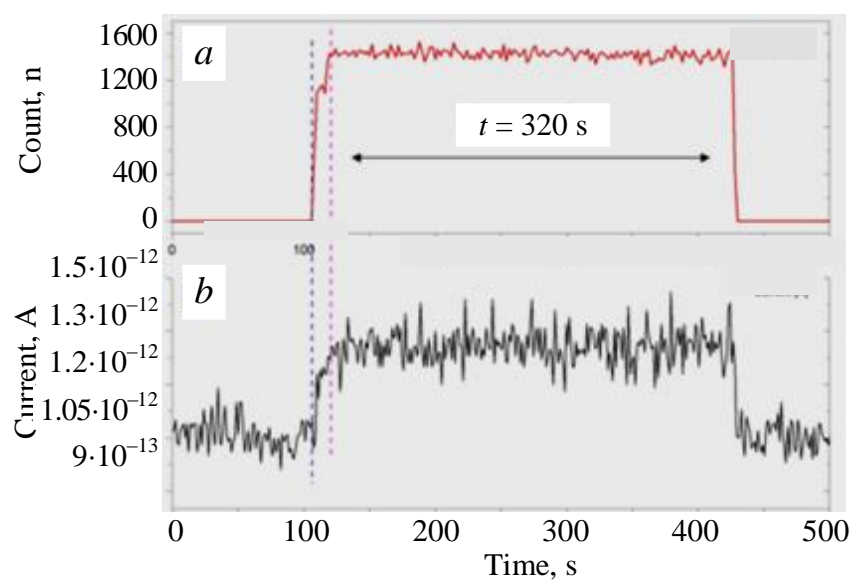

Fig. 7. $14 \mathrm{MeV}$ neutron monitor (a); current signal generated by the SPND_Cr $(b)$

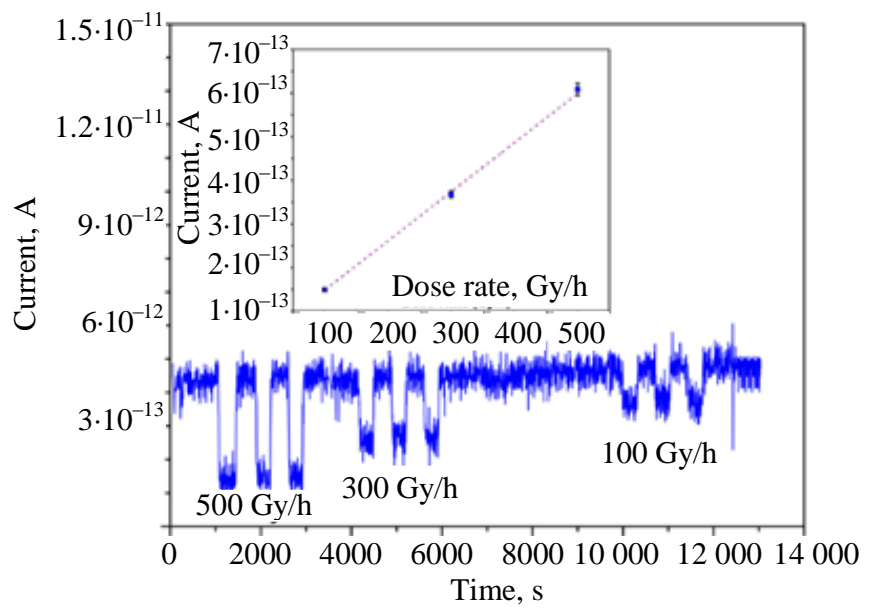

Fig. 8. Calibration of the SPND_Cr: linearity between the current signal and the neutron dose source. The signal detected by the SPND_Cr, when $14 \mathrm{MeV}$ neutrons are injected, is shown in Fig. 7; Fig. 7, $a$ presents the neutron monitor, while Fig. 7, $b$ shows a measured current signal.

Fig. 8 shows the SPND_Cr detector calibration: the linearity of the signal generated by the SPND_Cr while changing the neutron dose rate is displayed.

The SPBD_Cr can also detect gamma rays: Fig. 9 shows a comparison between current signals generated by the SPND_Cr detecting neutrons and gamma rays. Note the opposite polarities of the current produced by $14 \mathrm{MeV}$ neutrons and gammas. This could be predicted by a Monte-Carlo simulation.

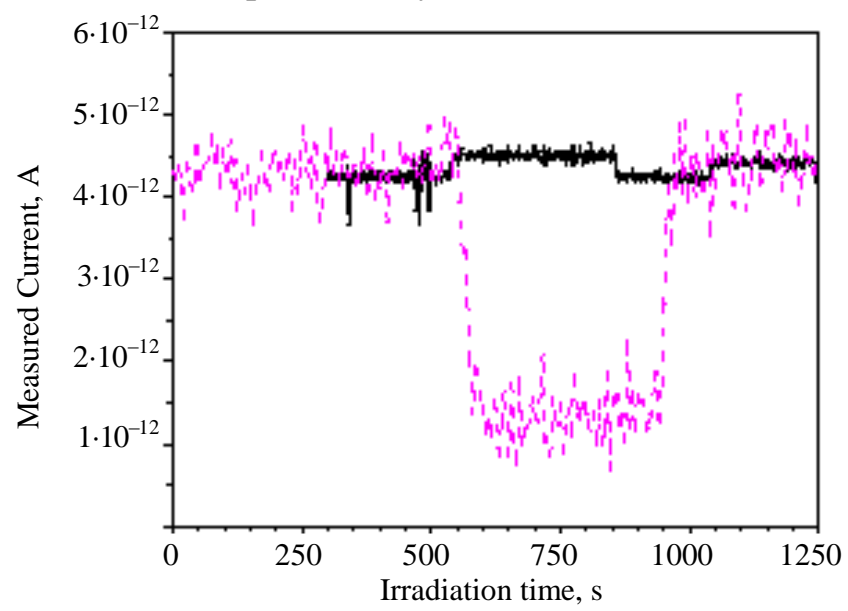

Fig. 9. SPND_Cr current signals generated with FNG $14 \mathrm{MeV}$ neutrons and the CALLIOPE ENEA ${ }^{60} \mathrm{Co}$ gamma ray source (note the opposite polarity of the signals): $\_-14 \mathrm{MeV}$ neutrons, - - - — gamma-rays

\section{CONCLUSIONS}

A tokamak-based FFH reactor is a complex system, which includes three subsystems: i) a tokamak neutron source, ii) a fusion blanket, iii) a fission blanket. These subsystems need their diagnostics and controls. The FFH reactor is a tokamak with low fusion gain, but working with very long pulses (at least $3 \mathrm{hrs)}$ and high availability (75\%); it is a low power DEMO-like device: the integrated in time neutron fluence $\left(3 \cdot 10^{24} \mathrm{n} / \mathrm{m}^{2}\right)$ is three times that of ITER, in one year. The evaluated neutron fluence means that from the point of view of diagnostic technology, the ITER system design can be used as a template, but some add itional R\&D on the damage of the main components like the mirrors and waveguides exposed to plasma are required. Tokamak plasma control includes the machine protection and plasma burn monitoring, which can be done using a minimum DEMO-like [6] set of diagnostics and actuators including plasma density and temperature diagnostics, as well as spectroscopy for plasma impurity detection. In this paper, the fusion and fission blanket diagnostic technology solutions are discussed and characterization measurements of $14 \mathrm{MeV}$ neutron diamond detectors for fusion blanket and the SPND are given in detail. The diamond detectors are very promising as neutron sensors for DEMO-like devices i.e., high neutron flux environment. The SPND can be used or the neutron measurements on the fission blanket being very robust and compact: Chromuim-based SPND are currently studied and considered to be suited for the detection of high energy $14 \mathrm{MeV}$ neutrons. 


\section{REFERENCES}

1. Stacey W.M. - J. Fus. Eng., 2009, vol. 28, p. 328-333.

2. Kotschenreuther M.K. et al. — Fus. Eng. Des., 2009, vol. 84, p. 83-88.

3. ITER Physics Basis. - Nucl. Fusion, 1999, vol. 39, p. 2541, and ibid., 2007, vol. 47, p. 5337.

4. Orsitto F.P. et al. - Nucl. Fusion, 2016, vol. 56, p. 026009.

5. Orsitto F.P. Fusion for neutrons and subcritical nuclear fission. - AIP Conf. Proc. 2012, vol. 1442, p. 289.

6. Orsitto F.P. - In: FUNFI2 Proc. 2017 ENEA ISBN 978-88-8286-357-9, ed. A. Pizzuto and F.P. Orsitto; https:// www.enea.it/it/seguici/pubblicazioni/edizioni-enea/2017/FUNFI2-2nd-International-Conference-on-Fusion-Fission, p. 131.

7. Cazzaniga C. et al. - Rev. Sci. Instr., 2014, vol. 85, p. $11 \mathrm{E} 101$.

8. Giacomelli L. et al. — Rev. Sci. Instr., 2016, vol. 87, p. 11D822.

9. Goldstein N.P., Todt W.H. — IEEE Trans Nuclear Science, 1979, vol. NS-26, p. 916.

10. Kadomtsev B.B. - Fiz. Plazmy, 1975, vol. 1, p. 531 [Sov. J. Plasma Phys., 1975, vol. 1, p. 295].

11. Orsitto F.P. et al. - In: 39th EPS/ICPP, 2012. Stockholm, paper 2.154 - Physics driven scaling laws for similarity experiments.

12. Romanelli M., Romanelli F., Zonca F. On the optimal choice of the dimensionless parameters of burning plasma physics experiments. - In: 28th EPS Conference on Contr. Fusion and Plasma Phys. Funchal, 18-22 June 2001, ECA 2001, vol. 25A, p. 697700 .

\section{AUHTORS}

Francesco Paolo Orsitto, ENEA Department for Fusion and Nuclear Safety, C.R. Frascati, v E. Fermi 45, 00044 Frascati, Italy, francesco.orsitto@enea.it

Maurizio Angelone, ENEA Department for Fusion and Nuclear Safety, C.R. Frascati, v E. Fermi 45, 00044 Frascati, Italy

Marco Tardocchi; Istituto per la Scienza e Tecnologia dei Plasmi CNR, Milano, Italy

Received 15 January 2021

Revised 16 March 2021

Accepted 25 March 2021

Problems of Atomic Science and Technology Ser. Thermonuclear Fusion, 2021, vol. 44, issue 2, pp. 78-85 